ERRATUM

C. Karatzaferi $\cdot$ A. de Haan $\cdot$ R.A. Ferguson

W. van Mechelen $\cdot$ A.J. Sargeant

\title{
Phosphocreatine and ATP content in human single muscle fibres before and after maximum dynamic exercise
}

Published online: 26 April 2001

(C) Springer-Verlag 2001

Pflügers Arch - Eur J Physiol (2001)

DOI $10.1007 / \mathrm{s} 004240100552$

The affiliation of the corresponding author and her present address were unfortunately transposed. The correct information is given here.

The online version of the original article can be found at http://dx.doi.org/10.1007/s004240100552

C. Karatzaferi ( $)$ A. de Haan · A. Ferguson · A.J. Sargeant Neuromuscular Biology Research Group,

Manchester Metropolitan University, Alsager ST7 2HL, UK

A. de Haan · A.J. Sargeant

Institute for Fundamental

and Clinical Human Movement Sciences,

Vrije University, Van der Boechorststraat 9,

Amsterdam 1081 BT, The Netherlands

W. van Mechelen

EMGO Institute and Department of Social Medicine,

Faculty of Medicine, Vrije University, Van der Boechorststraat 9,

Amsterdam 1081 BT, The Netherlands

Present address:

C. Karatzaferi, Department of Biochemistry \& Biophysics,

Box 0448. University of California San Francisco,

San Francisco CA 94143, USA

e-mail: ck@itsa.uscf.edu

Tel.: +1-415-476-1975, Fax: +1-415-476-1902 